\title{
Acute coronary syndrome with ST segment elevation in a patient with Addison disease: Case report and brief review of physiopathological mechanisms: A case study
}

\author{
MINELA AIDA MARANDUCA ${ }^{1 *}$, CRISTIAN STATESCU $^{2 *}$, RADU ANDY SASCAU $^{2}$, NICOLETA DIMA $^{2}$, \\ LOREDANA LILIANA HURJUI ${ }^{1}$, DRAGOMIR NICOLAE SERBAN ${ }^{1}$ and IONELA LACRAMIOARA SERBAN ${ }^{1}$ \\ Departments of ${ }^{1}$ Physiology and ${ }^{2}$ Internal Medicine, \\ ‘Grigore T. Popa' University of Medicine and Pharmacy, 700115 Iasi, Romania
}

Received April 16, 2019; Accepted December 31, 2019

DOI: $10.3892 /$ etm.2020.8855

\begin{abstract}
The adrenal gland serve important roles in the modulation of the immune response, the adjustment of blood pressure, the stress reaction via glucocorticoids and the hydroelectrolytic balance via mineralocorticoids. Primary adrenal insufficiency, known as Addison disease, is characterized by a decrease in glucocorticoid secretion (cortisol) and, more rarely, by a hyposecretion of mineralocorticoids (aldosterone). The production of cortisol, which is a hormone that helps the body respond to stress, is regulated in the brain, the hypothalamus and the pituitary gland. The hypothalamus stimulates the pituitary gland to produce adrenocorticotropic hormone, which stimulates cortisol production from the adrenal gland. If left untreated, Addison disease has a high mortality rate. Corticotherapy used in the treatment of Addison disease is associated with a certain cardiovascular risk. The proatherogenic effect of corticoids is based on the chronic inflammatory response of the vascular wall to a series of events. The aim of the current case report was to review the pathophysiological mechanisms and interactions that may lead to the onset of acute coronary syndrome with ST elevation in a patient with Addison disease.
\end{abstract}

\section{Introduction}

The primary insufficiency of adrenal cortex was first described by Thomas Addison, in 1855. This had been a fatal condition

Correspondence to: Professor Dragomir Nicolae Serban, Department of Physiology, 'Grigore T. Popa' University of Medicine and Pharmacy, 16 University Street, 700115 Iasi, Romania

E-mail:dnserban@yahoo.com

*Contributed equally

Key words: Addison disease, cortisol, aldosterone, coronary syndrome, corticotherapy until 1949, when Kendall, Sarett, and Reichstein introduced the substitution therapy with synthetic glucocorticoids. The most common cause of primary adrenal insufficiency is autoimmune adrenalitis (1). Other causes are represented by adrenoleukodystrophy (2), bilateral hemorrhagic adrenal infarction $(3,4)$, infectious adrenalitis $(5,6)$, and adrenal insufficiency induced by administration of synthetic cortisol (7).

Prevalence of Addison disease in the general population in Europe is of 93-144 cases per million and it is estimated that its incidence will reach 4.4-6 new cases per million per year (8). From a physiopathological perspective, Addison disease is characterized by a deficit of glucocorticoid and mineralocorticoid hormones, with an increase in blood plasma ACTH. Mineralocorticoids are known as hormones of sodium and potassium homeostasis. Aldosterone, the most active mineralocorticoid, acts mostly upon the distal and collecting tubules of the kidney, to stimulate sodium and water reabsorption, altogether with potassium excretion (Fig. 1). The general effect of aldosterone is the increase of volemia and arterial blood pressure. Therefore, the deficit of mineralocorticoids leads to: Hyponatremia and hyperkalemia, severe dehydration, blood plasma hypertonia, acidosis, decreased circulating blood volume, arterial hypotension, and even cardiovascular failure. On the other hand, the most important effects of glucocorticoids include: Hyperglycemia through the stimulation of gluconeogenesis, increased arterial blood pressure, anti-inflammatory and immunosuppressive activity. Overall, the deficit of glucocorticoids causes arterial hypotension, severe sensitivity to insulin and disorders in the metabolism of carbohydrates, proteins and lipids.

The association between Addison disease and acute coronary syndrome is rare. The physiopathological mechanisms that cause the acute coronary syndrome with ST segment elevation in Addison disease are partially known. The acute coronary syndrome occurring in response to severe endothelial injury is a major stress form, which stimulates the hypothalamus-hypophysis-adrenal axis, which thereafter modulates the complex neurovascular and hormonal response. The functional hypoadrenalism is accompanied by significant morbidity-mortality in the critical patient (9). 


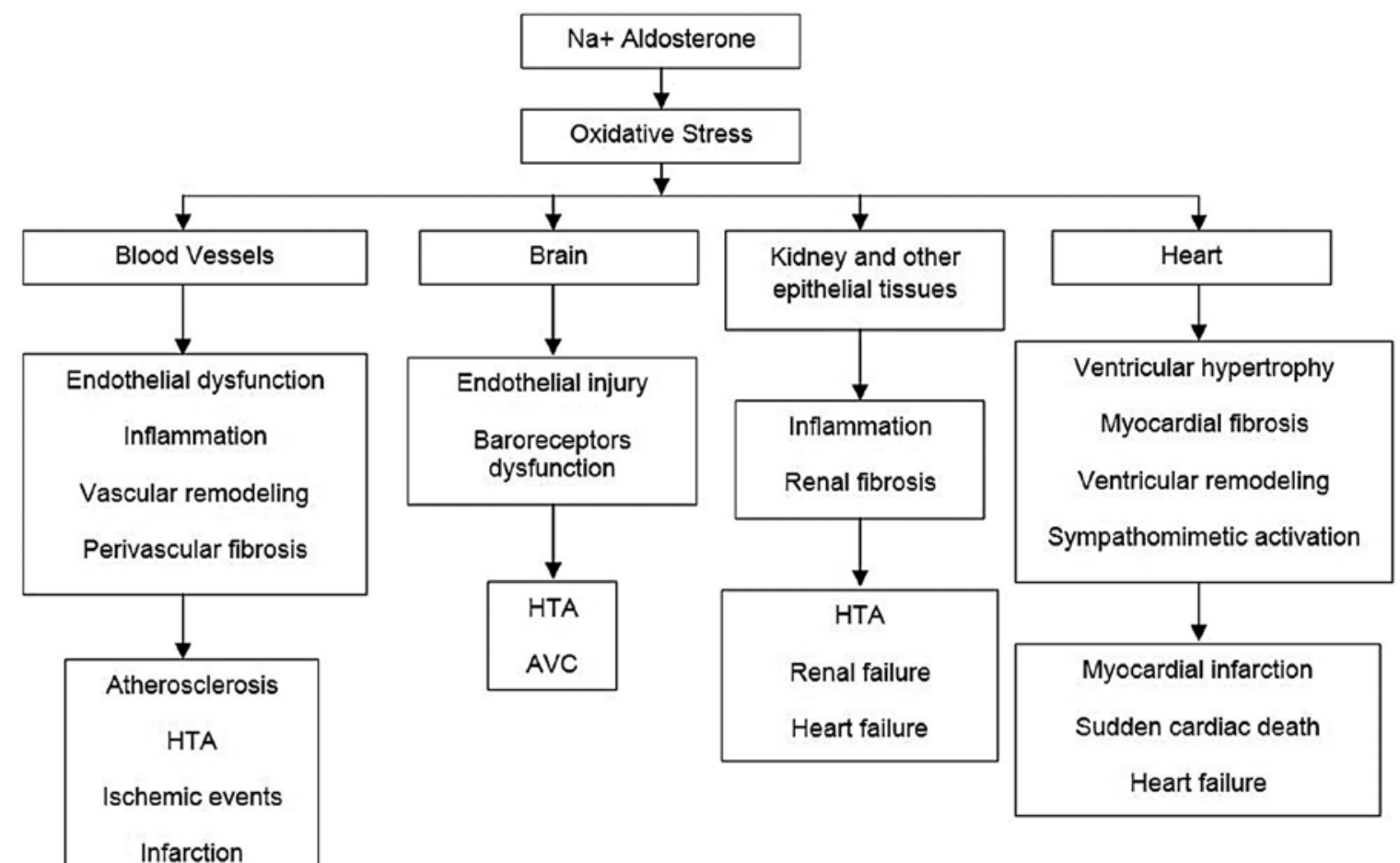

Figure 1. A schematic indicating the cardiovascular effects of aldosterone. HTA, arterial hypertension; AVC, stroke.

\section{Case report}

A 71-year-old woman has been brought to the hospital as an emergency case (by ambulance), for dehydration syndrome and lipothymic condition. The patient has hereditary/collateral history in the cardiovascular sphere: Father with stroke and a sister with myocardial infarction. She had been diagnosed with Addison disease 30 years ago (i.e., at her age of 41). She is under treatment with prednisone $5 \mathrm{mg}$ /day. Her last endocrinological examination took place 10 years ago (i.e., at her age of 61). She was hysterectomized for cervical neoplasm 2 years ago (i.e. at her age of 69).

The objective examination upon admission shows: Altered general condition, without fever, normal weight (BMI $22.2 \mathrm{~kg} / \mathrm{m}^{2}$ ), pale dehydrated teguments and mucosa, post-hysterectomy median scar, arterial blood pressure $60 / 40 \mathrm{mmHg}$, heart rate $95 / \mathrm{min}$, rhythmic cardiac sounds, aortic systolic murmur III/VI with irradiation on both carotids, lower limbs varices, enlarged abdomen through adipose panicle, mobile with breath, diffusely painful at deep palpation in the inferior abdominal level, palpable liver at the right costal margin, vesical catheter à demeure (normochromic urine).

Biological explorations upon admission show: Severe hyponatremia (124 mmol/l) with hypochloremia (92 mmol/l); acidosis (alkaline reserve $17 \mathrm{mmol} / \mathrm{l}$ ); nitrogen retention syndrome (urea $93 \mathrm{mg} / \mathrm{dl}$; creatinine $2.34 \mathrm{mg} / \mathrm{dl}$ ); hyperglycemia $(148 \mathrm{mg} / \mathrm{dl})$; leukocytosis $\left(10,460 / \mathrm{mm}^{3}\right)$ with lymphopenia $(15.7 \%)$ and monocytosis $(13 \%)$; thrombocytosis $\left(616,000 / \mathrm{mm}^{3}\right)$; hypocholesterolemia (total cholesterol $56 \mathrm{mg} / \mathrm{dl}$; LDL-cholesterol $20 \mathrm{mg} / \mathrm{dl}$, HDL-cholesterol $28.4 \mathrm{mg} / \mathrm{dl}$ ); hypotriglyceridemia (48 mg/dl); significant glycosuria at the urinalysis. BNP(natriuretic type $\mathrm{B}$ peptide) was normal upon admission. Electrocardiogram was also normal at the time of admission (Fig. 2).
Along the first $24 \mathrm{~h}$ from arrival to the Emergency Admission Unit, the patient was the subject of the following events, step by step: i) positive inotropic support and hydro-electrolytic and acid-base rebalancing; ii) admission to Endocrinology Clinic; iii) anginous pain and electrocardiographic aspect of extended acute inferior and anterior myocardial infarction (Fig. 3A and B), thus transfer to the Coronary Intensive Therapy Unit (Fig. 4), at the moment of transfer the myocytolysis enzymes being within normal limits and iv) confirmation of infarction diagnosis and immediate thrombolytic therapy, which proved to be successful. During monitorization in the Coronary Intensive Therapy Unit, after for ten days, another acute Addison episode occurred and the patient was again subjected to rebalancing, but this time the endocrinologist opinion was asked for and the decision was taken to increase the prednisone dose to $7.5 \mathrm{mg} /$ day $(5 \mathrm{mg}$ each morning and $2.5 \mathrm{mg}$ each afternoon).

The positive diagnosis of acute myocardial infarction was based on the clinical and electrocardiographic criteria. Thrombolysis was applied, using Metalyse 10,000 U, with clear subsequent favorable evolution (Figs. 5,6), without an increase of the myocardial cytolysis enzymes. In fact, myocardial enzymes, including troponin, were normal both before and after thrombolysis. Echocardiography performed during chest pain showed hypokinesis of the left ventricular apex and hypokinesis of the lower wall, with an ejection fraction in normal limits $(50 \%)$. Emergency coronary angiography could not be performed, because the service was unavailable at that time.

The clinical examination did not reveal cushingoid manifestations (as possible adverse effect of an uncontrolled glucocorticoid replacement therapy), while hormone measurements showed the level of cortisol was $10.6 \mu \mathrm{g} / \mathrm{dl}$ and that of 


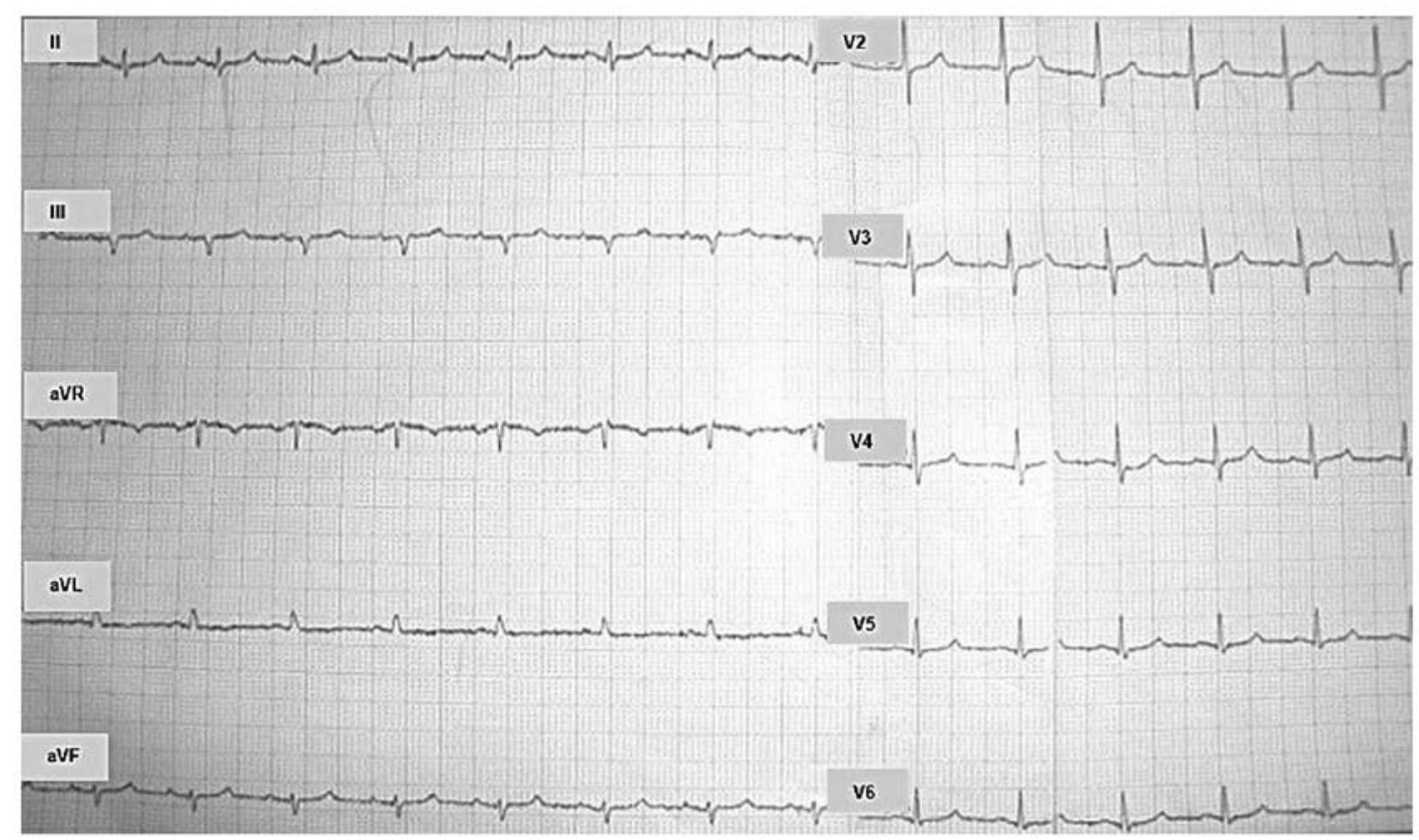

Figure 2. Electrocardiogram (ECG) upon hospital admission. Heart rate (HR) 91/min; normal intermediary electrical axis of the heart; SR aspect of the QRS complex. The usual denominations are used for the following: ECG waves (Q, R, S, and T; a non-capital letter refers to a small amplitude of the respective wave); standard bipolar ECG leads (I, II, and III); amplified unipolar ECG leads of the limbs (aVR, aVL, and aVF); thoracic (precordial) unipolar ECG leads ( $\mathrm{V}_{1}$ to $\mathrm{V}_{6}$ ).

A

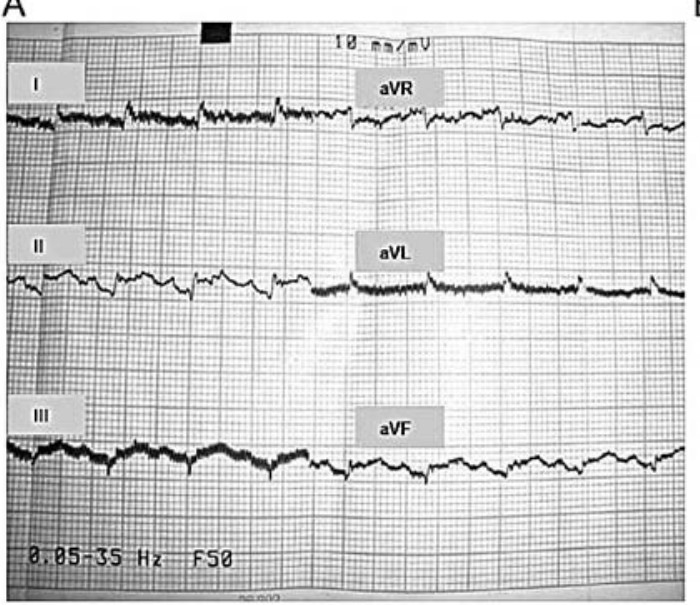

B

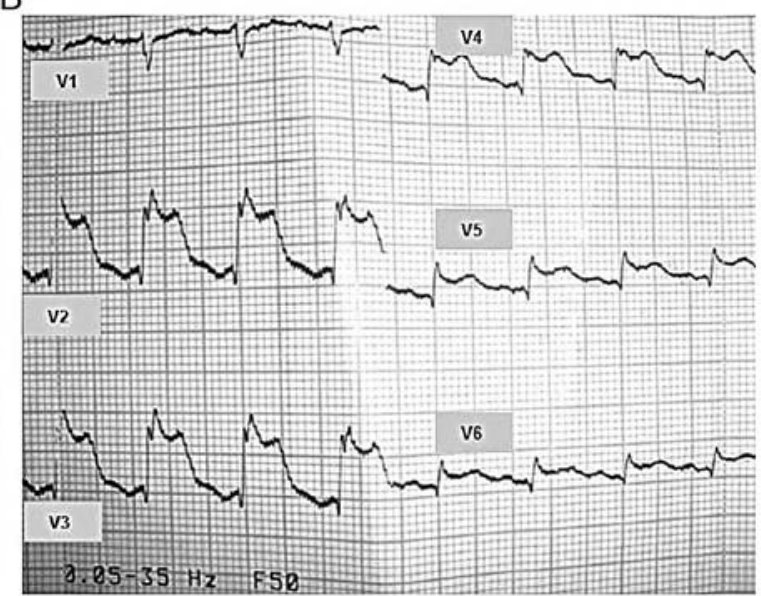

Figure 3. Electrocardiogram (ECG) during angina. Traces correspond to the standard leads and (A) unipolar leads of the limbs and (B) to the thoracic (precordial) leads. Analysis: Heart rate (HR) 116/min; normal intermediary electrical axis of the heart; qR aspect of the QRS complex and ST segment elevation in leads $\mathrm{I}, \mathrm{aVL}, \mathrm{V}_{5}$, and $\mathrm{V}_{6}$; QRS complex appears as a large monophasic wave in leads $\mathrm{V}_{2}, \mathrm{~V}_{3}$, and $\mathrm{V}_{4}$. The usual denominations are used for the following: ECG waves (Q, R, S, and T; non-capital letters refer to a small amplitude of the respective wave); standard bipolar ECG leads (I, II, and III); amplified unipolar ECG leads of the limbs (aVR, aVL, and aVF); thoracic (precordial) unipolar ECG leads ( $\mathrm{V}_{1}$ to $\left.\mathrm{V}_{6}\right)$.

ACTH was $398 \mathrm{pg} / \mathrm{ml}$. The abdominal CT performed shows, on the topography of the adrenal glands, two inhomogeneous iodophile formations, with calcareous structure.

So, prednisone was increased, from the previous dose of $5 \mathrm{mg} / \mathrm{day}$ to the current dose of $7.5 \mathrm{mg} / \mathrm{day}$, with the indication to increase the dose up to $10-15 \mathrm{mg}$ /day in case this was required by intercurrent stress events. The lower prednisone dose, of $5 \mathrm{mg} / \mathrm{day}$, proved to be insufficient in situations of superimposed acute events, allowing manifest Addison crisis to occur. With this higher prednisone dose, the patient has been stable thereafter, without any acute cardiovascular or endocrinological manifestations.

\section{Discussion}

Cardiovascular diseases constitute an important public health issue in industrialized countries, in terms of both morbidity and mortality. The most important mortality cause in the entire world is atherosclerosis. The most feared complication of chronic inflammation of the vascular wall, with the highest mortality rate, is the acute coronary syndrome with ST segment elevation (10). Atherosclerosis produces rigidity, narrowing and obstruction of coronary arteries. Inflammation represents the key element in the initiation, progression and destabilization of the atheromatous plaque (10). Endothelial 


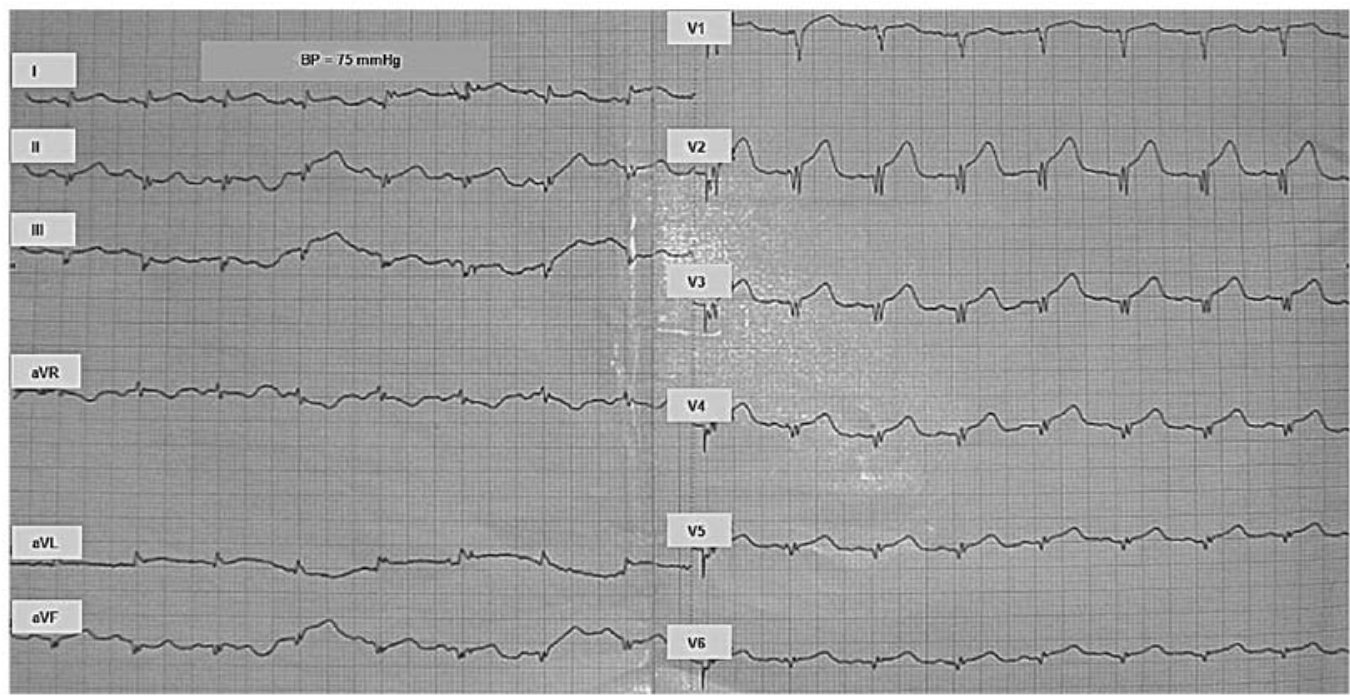

Figure 4. Electrocardiogram in the Cardiologic Clinic. Heart rate (HR) 99/min; normal intermediary electrical axis of the heart; arterial blood pressure (BP) $75 \mathrm{mmHg}$. The QRS complex has the following aspects: qR in leads I, II, aVL, $\mathrm{V}_{5}$, and $\mathrm{V}_{6}$; QS in leads III, aVF, and $\mathrm{V}_{1}$; QrS in leads $\mathrm{V}_{1}, \mathrm{~V}_{2}$, and $\mathrm{V}_{3}$. ST segment elevation of ascending type is present in preordial leads $\mathrm{V}_{2}$ to $\mathrm{V}_{5}$. The usual denominations are used for the following: $E C G$ waves (Q, R, $S$, and T; non-capital letters refer to a small amplitude of the respective wave); standard bipolar ECG leads (DI, DII, and DIII); amplified unipolar ECG leads of the limbs (aVR, $\mathrm{aVL}$, and aVF); thoracic (precordial) unipolar ECG leads $\left(\mathrm{V}_{1}\right.$ to $\left.\mathrm{V}_{6}\right)$.

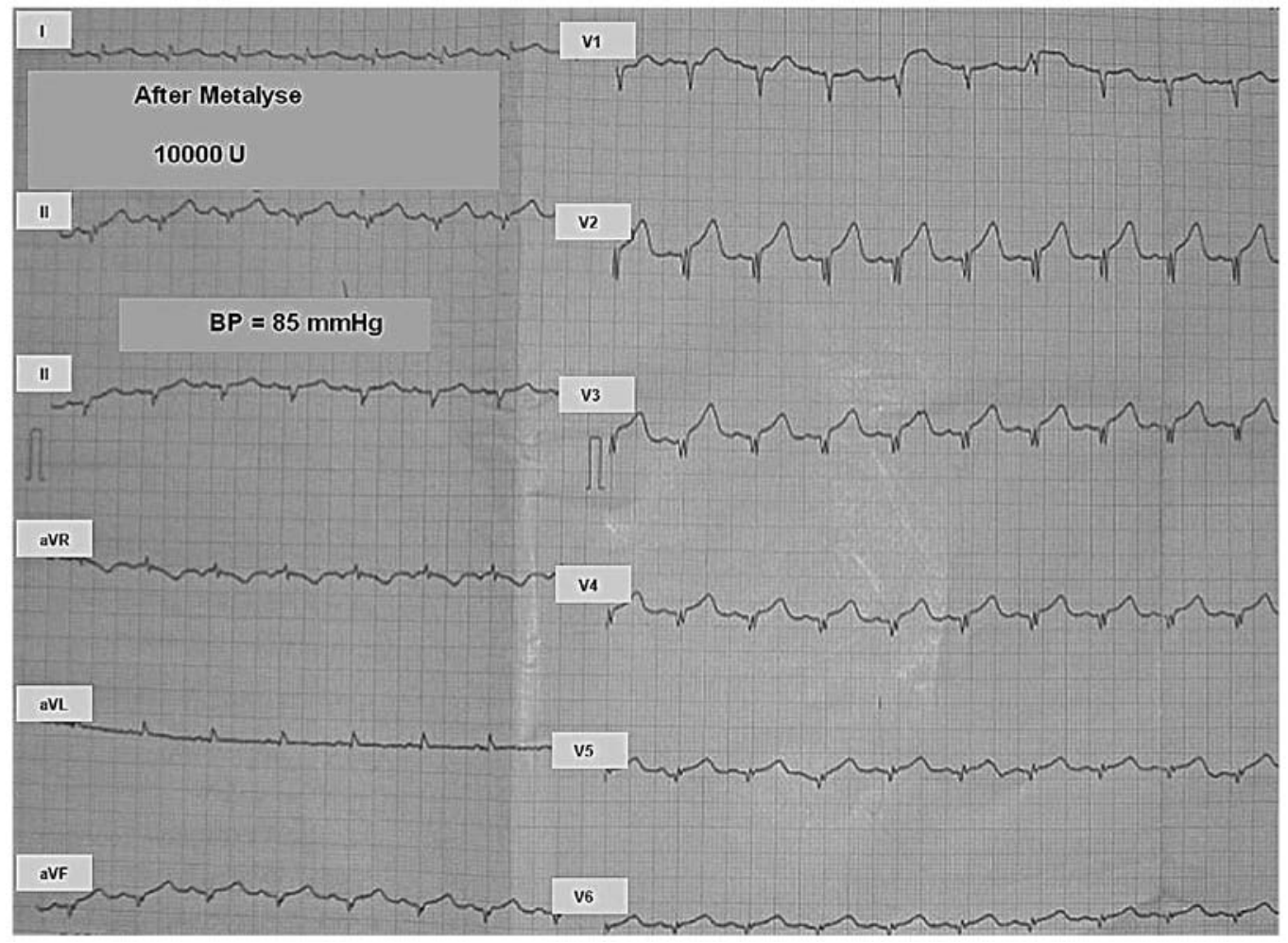

Figure 5. Electrocardiogram (ECG) immediately after Metalyse 10,000 u. Heart rate (HR) 90/min; normal intermediary electrical axis of the heart; arterial blood pressure (BP) $85 \mathrm{mmHg}$. The QRS complex has the following aspects: $\mathrm{qR}$ in leads I, II, aVL, $\mathrm{V}_{5}$, and $\mathrm{V}_{6}$; $\mathrm{QS}$ in leads III, aVF, and $\mathrm{V}_{1}$; QrS in leads $\mathrm{V}_{2}$, $\mathrm{V}_{3}$, and $\mathrm{V}_{4}$. ST segment elevation of ascending type is present in precordial leads $\mathrm{V}_{2}$ to $\mathrm{V}_{5}$. The usual denominations are used for the following: ECG waves (Q, R, S, and T, where non-capital letters refer to a small amplitude of the respective wave); standard bipolar ECG leads (I, II, and III); amplified unipolar ECG leads of the limbs (aVR, aVL, and aVF); thoracic (precordial) unipolar ECG leads $\left(\mathrm{V}_{1}\right.$ to $\left.\mathrm{V}_{6}\right)$.

dysfunction is currently considered the trigger factor in the pathogenesis of atherosclerotic plaque. Pro-inflammatory cytokines, such as TNF-alpha (tumor necrosis factor) (11) and IL-1 beta (interleukin 1) (12) act on endothelial cells to initiate a cascade of events that ultimately affect the endothelium anti-adhesive and anticoagulant properties and also its permeability. Alteration of endothelial permeability allows LDL accumulation in the heart and favors the adhesion of circulating monocytes/macrophages (13) and the formation of thrombi through the increase of the pro-aggregant and pro-coagulant 


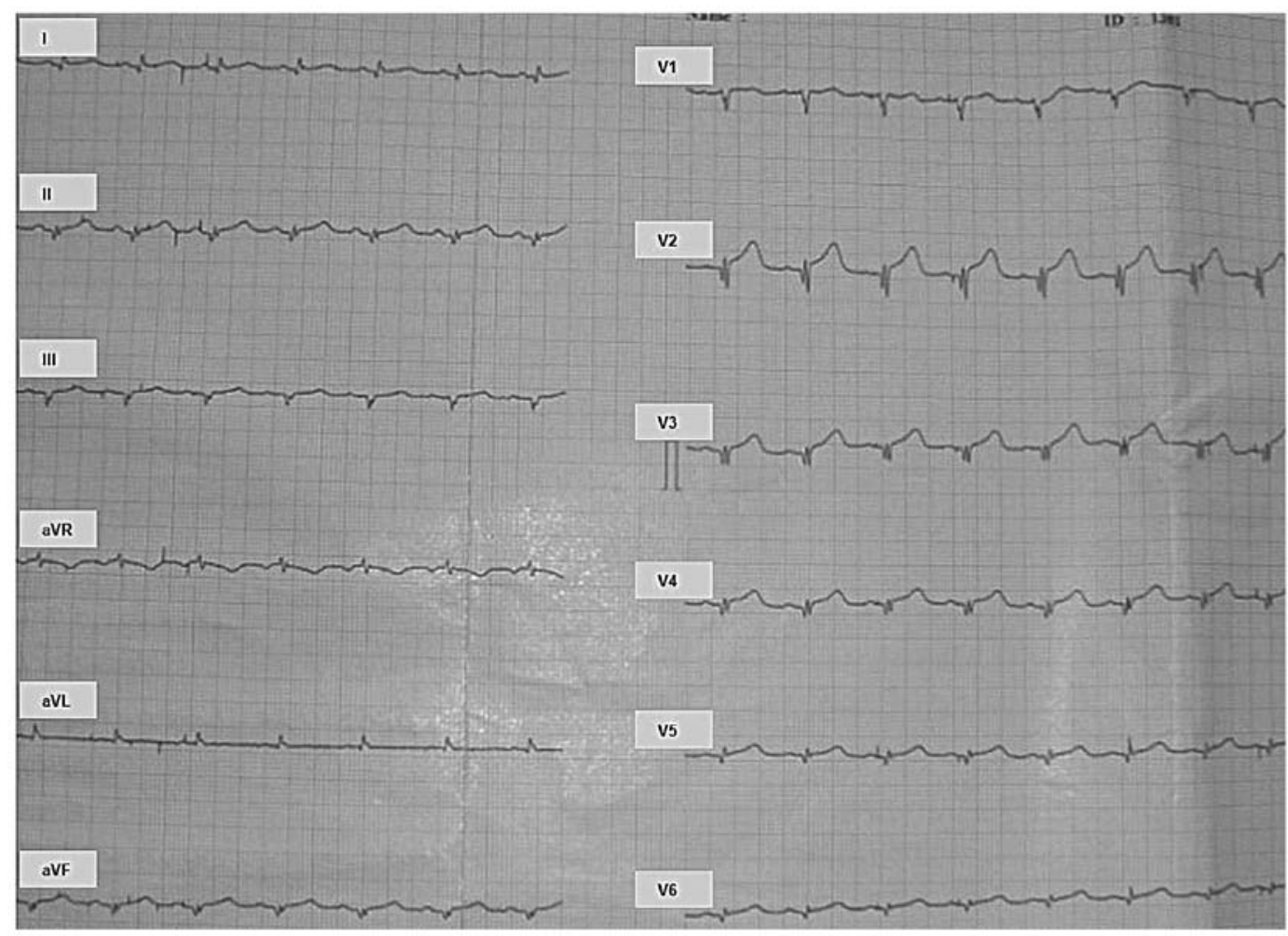

Figure 6. Electrocardiogram one hour after Metalyse 10,000 u. Heart rate (HR) 90/min; normal intermediary electrical axis of the heart; arterial blood pressure (BP) $85 \mathrm{mmHg}$. The QRS complex has the following aspects: qR in leads I and aVL, $\mathrm{V}_{5}$, and $\mathrm{V}_{6}$; $\mathrm{Qr}$ in leads II and aVF, QS in lead $\mathrm{V}_{1}$; qrS in leads $\mathrm{V}_{2}, \mathrm{~V}_{3}$, and $\mathrm{V}_{4}$. ST segment elevation of ascending type is present in precordial leads $\mathrm{V}_{2}$ to $\mathrm{V}_{5}$. The usual denominations are used for the following: ECG waves $(\mathrm{Q}, \mathrm{R}$, $\mathrm{S}$, and $\mathrm{T}$, where non-capital letters refer to a small amplitude of the respective wave); standard bipolar ECG leads (I, II, and III); amplified unipolar ECG leads of the limbs (aVR, aVL, and aVF); thoracic (precordial) unipolar ECG leads $\left(\mathrm{V}_{1}\right.$ to $\left.\mathrm{V}_{6}\right)$.

functions. Unfortunately, no cytokines were measured in the particular clinical case under discussion here.

Cortisol and ACTH are involved in atherogenesis, by modulation of the endothelial functions, by recruitment of circulating monocytes and their differentiation into macrophages, and by production of pro- and anti-inflammatory interleukins. Furthermore, these hormones are involved in development of acute coronary syndrome, by modulating platelet aggregation and thrombogenesis (14). Coronary atherosclerosis has a multi-factorial etiology, which includes non-modifiable factors (age, male sex, family predisposition) and modifiable factors (dyslipidemia, arterial hypertension, smoking, diabetes mellitus, obesity, sedentary lifestyle). Coronary atherosclerosis is a silent process which evolves in stages of years or tens of years.

In the case of our patient, coronary atherosclerosis is the main cause for the acute myocardial infarction that she developed during hospitalization. As reasons for these circumstances we have the patient's age, the hereditary cardiovascular history, the presence of systolic murmur at the level of carotid arteries, as well as the fact that she is at menopause. It is known that the clinical manifestations of atherosclerosis occur after the fifth decade of life in women, when the anti-aterosclerotic protective effect of oestrogen gradually decreases at the onset of menopause.

Addison disease, also called primary corticoadrenal insufficiency, is a hypofunction of the adrenal gland. From a physiopathological perspective, the Addison disease appears as an insufficient secretion of glucocorticoid and mineralocorticoid hormones. The deficit of glucocorticoid hormones leads to arterial hypotension, dysfunctions in the metabolism of carbohydrates, lipids and proteins and the decrease of insulin sensitivity. The deficit of mineralocorticoid hormones leads to an increase of the sodium excretion and a decrease of the potassium excretion in urine, which leads to hyponatremia and hyperkalemia. In this context severe dehydration appears, accompanied by decreased circulating volume and arterial hypotension.

Clearly applicable to the case presented here, a more detailed analysis of the involved pathophysiological mechanisms reveals the following. Hyponatremia, severe dehydration and hypovolemia are accompanied by decreased blood pressure and consequently, decreased myocardial perfusion occurs. On a pre-existing atherosclerotic background, prolonged low blood pressure may contribute to myocardial infarction, with an oxygen supply-demand disproportion appearing in the myocardium. In Addison disease, low blood pressure occurs, on one hand by decreased cortisol synthesis, and on the other by severe hyponatremia, which leads to decreased water reabsorption and extreme dehydration, with decreased circulating blood volume. These factors may participate in destabilizing the atheroma plaque and in the onset of acute coronary syndrome with ST elevation. Such a mechanism is advocated for by the following aspects present at the time of hospitalization: Dehydrated teguments and mucous membranes at the clinical examination; arterial blood pressure $60 / 40 \mathrm{mmHg}$, severe hyponatremia (124 mmol/l). 
The depletion of endogenous glucocorticoids is correlated with the development of the myocardial dysfunction. In murine models, adrenalectomy was associated with an impairment of the myocardial contractility through the depletion of the microsomal phosphorylase activity and a significant reduction of calcium absorption in the sarcoplasmic reticulum. These lead to a glycogenolysis dysfunction and the depression of the myocardial contractility. Moreover, the glucocorticoids deficit reduces the expression of adrenergic receptors and adrenalin synthesis and affects the cardiovascular reactivity to catecholamines. These mechanisms could explain the severe myocardial dysfunction associated to adrenal insufficiency (15). However, we could not identify animal studies explaining mechanisms associated with the occurrence of acute coronary syndrome in adrenal insufficiency.

Treatment of Addison disease includes glucocorticoids. Glucocorticoids stimulate atherogenesis and vascular remodeling (16), via glucocorticoid and mineralocorticoid receptors, a phenomenon which involves the local enzyme 11b hydroxysteroid dehydrogenase (17). In case of prolonged cortisol treatment, the vasoconstriction that sets in is a consequence of the decrease of nitric oxide production at the vascular level (18). At the same time, the administration of glucocorticoids produces an imbalance between the vasoconstrictor and vasodilating factors, through decreased synthesis of vasodilating prostacyclin and the increase of the vasoconstricting thromboxane (19). Our patient was diagnosed with Addison disease 41 years ago, thus she received substitution treatment with prednisone starting at that time. Prolonged administration of glucocorticoids increases the risk of cardio-vascular events (20), but in patients with Addison disease the adequate corticosteroid treatment is required as substitute and the risk of cardio-vascular events is minimal. Moreover, this patient had hypoadrenalism and only took a very small dose of glucocorticoid replacement therapy, so the mechanisms described in this paragraph actually do not apply. On the other side, only an overdose of glucocorticoids promotes pro-atherosclerotic dyslipidemia, as trigger for acute coronary syndrome, which is also not the case here.

Maybe above all, this case presentation shows an interesting acute issue, as follows. In the atherosclerotic context and with a relatively sufficient chronic corticoid substitution, a manifest acute Addison episode may lead to myocardial infarction. In our case the infarction was mainly of thrombotic cause, as shown by the successful thrombolysis. The hypotensive crisis lead to emergency hospitalization and the patient suffered the infarction the same day after admission and rebalancing. Even more, she had another Addison crisis ten days later, which imposed an increase in the corticoid substitution dose. The pathogenic complex behind this sequence of events involves all the aspects discussed above, regarding the atheroma in such conditions. Maybe with a special relevance of all the abrupt hemodynamic changes, reflected in major and sharp changes in shear stress, under circumstances of blunted flow-mediated dilation due to endothelial dysfunction.

To conclude, in case of a patient with Addison disease, the pre-existing coronary atherosclerosis is the main cause that leads to the development of acute coronary syndrome with elevation of ST segment. The severe hyponatremia, dehydration, and hypovolemia, all found in this adrenal cortical insufficiency, can be considered trigger factors, but they could not cause acute coronary syndrome without the pathological basis of atherosclerosis. Such factors, on a pre-existing atherosclerotic background, increase the risk of major cardiovascular events, such as acute myocardial infarction with ST-segment elevation, as in our case report. This multifactorial pathogenic scene needs to include thrombosis, coronary spasm and low blood pressure as causes of myocardial infarction. These three mechanisms are more or less related to the context of Addison disease and the required corticotherapy, as discussed above. Last but not least, the conclusion of this article is that corticoid substitution therapy, which may seem sufficient, can become insufficient along the evolution of cardiovascular disease (mainly with age), thus leading to the manifest Addison crisis and even to major ischemic events, as in the case discussed here.

\section{Acknowledgements}

Not applicable.

Funding

No funding was received.

\section{Availability of data and materials}

The datasets used and/or analyzed during the current study are available from the corresponding author on reasonable request.

\section{Authors' contributions}

MAM, CS, DNS and ILS contributed to conception and design of the current study. MAM, CS, RAS, ND and LLH acquired the data. All authors analyzed and interpreted the data. MAM and CS drafted the manuscript and RAS, ND, LLH, DNS and ILS revised it critically for important intellectual content. All authors gave final approval of the this version of the manuscript to be published.

\section{Ethics approval and consent to participate}

Informed consent was obtained from the patient.

\section{Patient consent for publication}

Informed consent has been obtained from the patient regarding the publication of the case details and any associated images.

\section{Competing interests}

The authors declare that they have no competing interests.

\section{References}

1. Erichsen MM, Løvås K, Skinningsrud B, Wolff AB, Undlien DE, Svartberg J, Fougner KJ, Berg TJ, Bollerslev J, Mella B, et al: Clinical, immunological, and genetic features of autoimmune primary adrenal insufficiency: Observation from a Norwegian registry. J Clin Endocrinol Metab 94: 4882-4890, 2009.

2. Kemp S, Berger J and Aubourg P: X-linked adrenoleukodystrophy: Clinical, metabolic, genetic and pathophysiological aspects. Biochim Biophys Acta 1822: 1465-1474, 2012. 
3. Rao RH, Vagnucci AH and Amico JA: Bilateral massive adrenal hemorrhage: early recognition and treatment. Ann Intern Med 110: 227-235, 1989.

4. Rao RH: Bilateral massive adrenal hemorrhage. Med Clin North Am 79: 107-129, 1995.

5. Bhatia E, Jain SK, Gupta RK and Pandey R: Tuberculous addison's disease: Lack of normalization of adrenocortical function after anti-tuberculous chemotherapy. Clin Endocrinol (Oxf) 48 355-359, 1998

6. Walker BF, Gunthel CJ, Bryan JA, Watts NB and Clark RV: Disseminated cryptococcos is in an apparently normal host presenting as primary adrenal insufficiency: Diagnosis by fine needle aspiration. Am J Med 86: 715-717, 1989.

7. Elias AN and Gwinup G: Effects of some clinically encountered drugs on steroid synthesis and degradation. Metabolism 29: $582-595,1980$

8. Nicolaides NC, Chrousos, Charmandari E. In: De Groot LJ, Chrousos G, Dungan K, Grossman A, Hershman JM, Koch C, Korbonits M, McLachlan R, New M, Purnell J, Rebar R, Singer F Vinik A, editors. Adrenal Insuffiency Endotext [Internet]. South Dartmouth (MA): MD Text.com, Inc.; 2000-2013.

9. Norasyikin AW, Norlela S, Rozita M, Masliza M, Shamsul AS and Nor Azmi K: Adrenal insufficiency in acute coronary syndrome. Singapore Med J 50: 962-966, 2009.

10. Sger HB and Nahrendorf M: Inflammation: A trigger for acute coronary syndrome. Q J Nucl Med Mol Imaging 60: 185-193, 2016.

11. Tabas I and Bornfeldt KE: Macrophage phenotype and function in different stages of atherosclerosis. Circ Res 118: 653-667, 2016.

12. Coll RC, Robertson AA, Chae JJ, Higgins SC, Munoz-Planillo R, Inserra MC, Vetter I, Dungan LS, Monks BG, Stutz A, et al: A small-molecule inhibitor of the NLRP3 inflammasome for the treatment of inflammatory diseases. Nat Med 21: 248-255, 2015.
13. Varol C, Mildner A and Jung S: Macrophages: Development and tissue specialization. Annu Rev Immunol 33: 643-675, 2015.

14. Fantidis P: The role of the stress-related anti-inflammatory hormones ACTH and cortisol in atherosclerosis. Curr Vasc Pharmacol 8: 517-525, 2010.

15. Shimizu M, Monguchi T, Takano T and Miwa Y: Isolated ACTH deficiency presenting with severe myocardial dysfunction. J Cardiol Cases 4: e26-e30, 2011.

16. Shokr M, Rashed A, Lata K and Kondur A: Dexamethasone associated ST elevation myocardial infarction four days after an unremarkable coronary angiogram-another reason for cautious use of steroids: A case report and review of the literature. Case Rep Cardiol 2016: 4970858, 2016.

17. Walker BR: Glucocorticoids and cardiovascular disease. Eur J Endocrinol 157: 545-559, 2007.

18. Rogers KM, Bonar CA, Estrella JL and Yang S: Inhibitory effect of glucocorticoid on coronary artery endothelial function. Am J Physiol Heart Circ Physiol 283: H1922-H1928, 2002.

19. Jun SS, Chen Z, Pace MC and Shaul PW: Glucocorticoids downregulate cyclooxygenase-1 gene expression and prostacyclin synthesis in fetal pulmonary artery endothelium. Circ Res 84: 193-200, 1999.

20. Yildirim U, Gulel O, Soylu K, Yuksel S and Sahin M: Steroid-induced recurrent myocardial ischemia. Rev Port Cardiol 33: 473.e1-4, 2014.

This work is licensed under a Creative Commons Attribution-NonCommercial-NoDerivatives 4.0 International (CC BY-NC-ND 4.0) License. 